\title{
From black and white to shades of grey
}

\section{A longitudinal study of teachers' perspectives on teaching sociocultural and subjective aspects of science}

\author{
Lotta Leden $^{1}$ (D) - Lena Hansson ${ }^{1}$ - Andreas Redfors ${ }^{1}$
}

Published online: 7 September 2017

(C) The Author(s) 2017. This article is an open access publication

\begin{abstract}
Traditional school science has been described as focused on indisputable facts where scientific processes and factors affecting these processes become obscured or left undiscussed. In this article, we report on teachers' perspectives on the teaching of sociocultural and subjective aspects of the nature of science (NOS) as a way to accomplish a more nuanced science teaching in Swedish compulsory school. The teachers $(N=6)$ took part in a longitudinal study on NOS and NOS teaching that spanned 3 years. The data consists of recorded and transcribed focus group discussions from all 3 years. In the analysis, the transcripts were searched for teachers' suggestions of issues, relevant for teaching in compulsory school, as well as opportunities and challenges connected to the teaching of these issues. The results of the analysis show that (a) the number of suggested issues increased over the years, (b) teachers' ways of contextualizing the issues changed from general and unprecise to more tightly connected to socio-scientific or scientific contexts, and (c) the number of both opportunities and challenges related to NOS teaching increased over the years. The most evident changes occurred from the beginning of year 2 when the focus group discussions became more closely directed towards concrete teaching activities. Tensions between the opportunities and challenges are discussed as well as how these can be met, and made use of, in science teacher education.
\end{abstract}

\section{Introduction and Background}

Research has shown that science teaching often focuses on a body of concepts and that uncertainties, processes behind the concepts, and connections to society are absent. As a consequence, voices have been raised to promote knowledge of "Whole Science" (Allchin 2011) and "salvaging science literacy" (Feinstein 2011). One step in that direction has been made through articulating nature of science (NOS) as an important learning object in curricula

Lotta Leden

lotta.leden@hkr.se

1 LISMA, Kristianstad University, 29188 Kristianstad, Sweden 
and policy documents (e.g., the Swedish national curriculum; Skolverket 2011). Moreover, extensive efforts have been made to implement NOS in the science classroom (see e.g., Akerson and Hanuscin 2007; Lederman and Lederman 2012; Clough and Olson 2012). Even though teachers' perspectives are part of these studies, more research focusing specifically on teachers' perspectives is needed in order to better understand how such efforts are received by teachers. In a previous study (Leden et al. 2015), we have shown that teachers perceived NOS teaching as something new. To change existing practices through, for example, including new elements in the teaching is often challenging. Previous research on challenges (e.g., Henke and Höttecke 2015; Höttecke and Silva 2011) has provided explanations as to why there often is a gap between research intentions and classroom practice. Teachers' perspectives constitute an important part in the attempt to understand this gap further. The present article contributes with longitudinal research on teachers' suggestions of issues, within the scope of sociocultural and subjective aspects that could be considered meaningful and possible to teach in compulsory school. ${ }^{1}$ Six teachers were followed for 3 years in their teaching and in focus group discussions.

The article adds to previous research by providing an in-depth report on these teachers' perspectives on both opportunities and challenges that follow from teaching sociocultural and subjective aspects of NOS. During focus group discussions, challenges and opportunities were negotiated among the teachers, which provide data on both tensions and consensus. Moreover, the longitudinal approach contributes with insights into how perspectives and suggestions can change over time through taking part in reflective discussions about NOS and NOS teaching. These results are useful in the development of NOS courses for teacher education and professional development.

Below, we present research that has been essential for understanding and interpreting teachers' discussions. This includes research on the overarching goals of science education often under the label of scientific literacy. It also includes research that is situated within the field of NOS teaching, in this case challenges and opportunities connected to NOS teaching and research on sociocultural and subjective aspects of NOS. The results section organizes the analysis of the empirical data in two sections related to NOS issues and opportunities and challenges. The discussions section highlights tensions in the teachers' discussions over the 3 years.

\subsection{Aims and Goals of School Science}

Traditionally, school science has been found to focus on a body of concepts and cook-book lab-activities with the aim to provide an insight into what is perceived as essential scientific concepts. In this kind of school science, few interactions between science, society, and culture come to light. Instead, knowledge is presented as discovered without problem, and without any influence from values, norms, interests, or specificities of the times or places of its creators (Zacharia and Barton 2004). In other words, school science most often deals with ready-made science (Latour 1987) where consensus has been reached long ago. The uncertainty or messiness of science in the making is seldom emphasized (Ruhrig and Höttecke 2015). Through such school science, myths about indisputable, objective knowledge and heroic scientists are implicitly and explicitly communicated to the students (Allchin 2003; McComas 1998).

\footnotetext{
${ }^{1}$ Swedish compulsory school comprises years 1 (age 7) to 9 (age 16).
} 
Achieving scientific literacy has been described as a goal of science education. However, literacy comes in many shapes and the definitions of scientific literacy in the research literature are diverging. Extensive reviews on the topic have been made (e.g., Deboer 2000; Hodson 2008; Roberts 2007). The relation between scientific literacy and knowledge of science concepts has been debated. However, Roberts (2007) argued that most research on literacy finds it impossible to be scientifically literate without having any knowledge of science concepts. Two broad approaches to scientific literacy have been described in the literature (Hodson 2008; Roberts 2007, 2011; Roberts and Bybee 2014). One of them takes its point of departure within science, and the other starts in science-related situations outside science, where the latter has often been referred to as critical scientific literacy or science for all. Roberts (2007) and Roberts and Bybee (2014) argued that one approach should not exclude the other, but instead contribute with different elements that need to be balanced in science education. Unfortunately, the debate and suggestions have often become polarized in a way that favors one approach over the other to an extent that the less favored is only represented in a very shallow way.

Furthermore, Roberts and Bybee (2014) followed up on Roberts' earlier review by studying scientific literacy trends over the past 10 years and came to the conclusion that the recent policy trends are directed towards putting more emphasis on starting points within science. This conclusion is supported by Feinstein et al. (2013) who argued that policy makers of today focus on producing science-ready students. However, if the goal for school science is to be less alienating and bring about "competent outsiders" (Feinstein 2011), or to create an interest and engagement in more and diverse student groups, a greater balance is needed (Zacharia and Barton 2004). Discussions regarding the goals and aims of school science are far from novel, but have been a topic at least since the beginning of the twentieth century (Rudolph 2005). It is also evident that the diverging goals will be connected to very different forms of teaching, where the focus on concepts has been known to follow strict patterns of teacher-centered transmission of knowledge (Bartholomew et al. 2004; Höttecke and Silva 2011).

An alternative to the strong focus on concepts has, as mentioned above, been described as an education aiming at "science for all" or "critical scientific literacy" (Hodson and Wong 2014). That is, a science that could be embraced as functional, meaningful (Allchin 2011, 2014), or useful in one form or another in everyday life (Feinstein 2011), as well as being connected to students' experiences and interests (Zacharia and Barton 2004). This kind of science teaching often has a starting point in situations outside science. Such school science has been discussed in terms of developing students' abilities to deal with uncertain knowledge and conflicting evidence through, among other things, being able to make judgements about trustworthiness and credibility and to use media as a source. In many cases, it is suggested that this should be done through authentic and context-rich activities (Allchin 2014; Feinstein et al. 2013; Hodson and Wong 2014). The project described here takes a point of departure in science education research on NOS. We argue, as many others (e.g., Allchin 2014; Hodson and Wong 2014; Yacoubian 2015), that NOS could be one piece in the puzzle of creating a more nuanced science for all, and in the long run lead to critical scientific literacy and competent outsiders.

\subsection{Sociocultural and Subjective Aspects of Science}

In research studies on NOS, sociocultural and subjective aspects of NOS have either been less emphasized than other aspects or less progress has been made regarding teachers' or students' 
understanding (Wong and Hodson 2010). Thus, they have been considered as particularly difficult and abstract to deal with both for teachers and students (Akerson et al. 2011). In order to explore these aspects further, this article specifically focuses on teachers' discussions about sociocultural and subjective aspects as a way to challenge black-and-white images of science in their science teaching.

Sociocultural and subjective aspects of science have often been included in frameworks that put forward ideas of what can be considered to be important aspects of NOS. In this article, we have chosen to treat sociocultural and subjective aspects as one NOS category due to their inherent interconnection. An example is personal values that are often categorized as part of subjective aspects (e.g., Lederman 2007). These values are however affected by various issues, such as cultural backgrounds, ideologies, and so forth that are often categorized as sociocultural issues. Thus, the two aspects are deeply intertwined and for the purpose of this study not necessary to separate.

The research literature has presented various descriptions of sociocultural and subjective aspects of science. For the purpose of this article, it is important to provide an account that shows some of the breadth in the suggestions from previous research. However, it is important to note that these suggestions are primarily based on either theoretical constructs or on suggestions from experts (e.g., scientists, science educators, philosophers of science), and not, as in the present article, on suggestions made by practitioners in ordinary science teaching situations. Some examples of issues are:

- Ways of organizing research, the communication of scientific results, and peer review (Abd-El-Khalick 2012; Allchin 2011; Erduran and Dagher 2014)

- Interactions between science and society through politics and economy (Allchin 2011; Erduran and Dagher 2014; Lederman 2007)

- Authority and prestige (Hodson and Wong 2014)

- Theory-ladeness (Abd-El-Khalick 2012; Lederman 2007)

- Cultural beliefs (Allchin 2011; Lederman 2007)

- Gender, class, or racial bias (Allchin 2011; Hodson and Wong 2014);

- Fraud (Allchin 2011)

- Motivations, personalities, mind-sets (Allchin 2011; Hodson and Wong 2014; Lederman 2007)

- Norms, traditions, and language of scientific communities (Erduran and Dagher 2014; Hodson and Wong 2014)

- Competition (Erduran and Dagher 2014)

In this article, teachers' perspectives and suggestions regarding the role of sociocultural and subjective issues in compulsory school make an important contribution to previous research.

\subsection{Challenges and Opportunities}

Needless to say, there are challenges connected to the introduction of new elements in the science classroom. Most teachers are deeply rooted in a school-science culture that has its starting point within science and uses the structured teaching formats connected to this way of viewing the goals of science education (Roberts 2011). This means that including new elements, both issues and teaching formats, that does not fit with the current teaching culture can be very challenging for teachers (Aikenhead 2006; 
Bartholomew et al. 2004; Höttecke and Silva 2011). In a recent study, Leden et al. (2015) reported on perspectives on NOS teaching put forward by teachers who had no previous NOS teaching experience. These teachers had a variety of ways of talking about NOS, but had a much smaller repertoire regarding NOS teaching. This was particularly evident for sociocultural and subjective issues of NOS. A short and by no means exhaustive list of other challenges that have been reported in the research literature on NOS teaching contains:

- A lack of teaching resources that can be embraced as adequate by the teachers (Abd-ElKhalick et al. 1998; Akerson and Hanuscin 2007; Hanuscin et al. 2011; Lakin and Wellington 1994, Höttecke and Silva 2011)

- NOS considered as an add-on even by teachers who regard it as important (Abd-ElKhalick et al. 1998; Clough and Olson 2012; Höttecke and Silva 2011)

- Teachers are unaccustomed to, and insecure regarding, the NOS teaching format and strategies (Bell et al. 2000; Herman et al. 2013; Lakin and Wellington 1994, Henke and Höttecke 2015, Leden et al. 2015)

- Concerns for students' abilities to deal with abstract or controversial issues (Abd-ElKhalick et al. 1998; Aikenhead 2006; Brickhouse and Bodner 1992; Hodson 1993; Lederman 1995; Leden et al. 2015)

- Concerns for the "good students" who are accustomed to memorize facts for the test (Aikenhead 2006; Leden et al. 2015)

Research studies have examined what teachers perceive as opportunities with NOS teaching to a surprisingly small extent. One interesting exception is Herman et al. (2015) who connected the "type of utility value" expressed by the teachers to their level of NOS implementation. Low implementers were vague in their reasons for why NOS should have a place in science teaching. Considered as vague reasons were notions that NOS "brings it down to the human level," and that science becomes more enjoyable and connected to everyday life (Herman et al. 2015). However, if teachers are to be able to overcome the obstacles of breaking with traditional school science, through teaching about NOS, it is important that they see the utility for NOS teaching in the endeavor to reach more overarching goals of science teaching (Herman et al. 2015; Höttecke and Silva 2011). Such overarching goals have to do with students' abilities to take part in, or make meaning of, socio-scientific debates (Hodson and Wong 2014) and to create competent outsiders (Feinstein 2011) - that is, goals that are "important for life well beyond formal schooling" (Herman et al. 2015, p.180).

\subsection{Aim of the Present Study}

Few studies have focused specifically on the teaching of sociocultural and subjective aspects of science, although many have mentioned the specific challenges connected to such teaching. Moreover, very few studies have thoroughly examined the opportunities related to such a teaching expressed by teachers. Therefore, the aim of this article is to longitudinally explore changes and trends in teachers' reflections on the teaching of sociocultural and subjective aspects of science. In this exploration, we have looked for teachers' suggestions for relevant issues as well as their reflections on opportunities and challenges. Through learning more about teachers' perspectives, 
insights can emerge that serve both pre- and in-service teacher education. Specific questions guiding the study are:

- What suggestions concerning the teaching about sociocultural and subjective aspects of science are raised by the teachers over the years?

- What opportunities and challenges concerning the teaching about sociocultural and subjective aspects of science are emphasized over the years?

\section{Method}

\subsection{Context}

In Sweden, science (i.e., biology, chemistry, and physics) is studied by all students throughout compulsory school. NOS is included in the current Swedish national curriculum (Skolverket 2011), and it has also been included in former versions for the last couple of decades (Johansson and Wickman 2012). References to different NOS aspects are made, both implicitly and explicitly, in the curriculum (Skolverket 2011), and the intention to make NOS part of science teaching is strengthened by an official commentary on the curriculum (Skolverket 2016). Commentaries (Skolverket 2016) are available for each subject with the purpose to help teachers interpret the goals of the curriculum. In the commentary, the term "nature of science" is specifically mentioned:

Knowledge about the nature of science is central in order to be able to distinguish between scientific information and other ways of describing the world. That kind of knowledge makes it possible for students to see how facts are connected to values, and to examine the interests and values behind certain positions. (Skolverket 2016, p. 30, our translation).

Furthermore, these documents emphasize that science should be introduced as "...a dynamic, creative, and up-to-date subject in constant development." (Skolverket 2016, p. 7, our translation). However, even if NOS is included in the national curriculum, it is important to note that there are no specific teaching materials developed that could provide guidelines for teaching. Furthermore, previous Swedish studies by Högström et al. (2006) and Gyllenpalm et al. (2010) have shown that the teaching of NOS is seldom mentioned by Swedish science teachers when they talk about science teaching.

Since the present article specifically examines teachers' perspectives on the teaching of sociocultural and subjective aspects of NOS, it is important to say something about how these are put forward in the Swedish national curriculum. In the overarching aims that cover science teaching in years 1-9 (7-16 years old), it is argued that "through teaching, pupils should be given the opportunity to develop perspectives on changes in the worldview of the sciences and obtain an insight into how the sciences and culture influence each other" (Skolverket 2011, p. 120 , official translation). Furthermore, different age groups have specific goals, where sociocultural and subjective aspects are included for all age groups, but with partly different focus. In the early years (1-3), the teaching is directed towards: "Narratives about science from earlier times, and the attempts of different cultures to understand and explain phenomena in nature." (Skolverket 2011, p.122, official translation), while for years 7-9 the teaching should also cover public discussions about social issues involving science, comparisons between scientific 
theories, and other descriptions, as well as how historical and contemporary discoveries "have been shaped and formed by worldviews" (Skolverket 2011, p. 124, official translation).

\subsection{Participants}

At the beginning of the project, 39 teachers answered the open-ended questionnaire VNOS-C (Lederman et al. 2002). The questionnaire (which was translated into Swedish in collaboration between three researchers) was used with a twofold purpose. First to, be able to analyze how Swedish teachers talk about NOS and second, to give them a first idea about what kind of issues NOS deals with so that they would know what they said "yes" to when we asked them to take part in the continuation of the project. Twelve teachers (two groups) who had teaching experiences covering all grades of compulsory school (years 1-9) and who had opportunities to meet were chosen to take part in a follow-up interview on NOS teaching. The analysis of the questionnaires and follow-up interviews (see Leden et al. 2015) served as a point of departure for the project. One of the two groups stayed on for the entire project. This group was formed by teachers who taught at four different schools (albeit half of the teachers belonged to the same school) and all but one of them had long teaching experience, i.e., 10 years or more (see Table 1 for details).

The teachers met for focus group discussions that were all held at one school, where three of the teachers taught. One of these three teachers, Mary, stopped teaching science after 2 years in the project, which made her leave the group. The teacher, Emma, who replaced Mary in science teaching took her place in the focus group from the beginning of year three. This was a decision based on ethical considerations since it would be inappropriate to exclude one of three science teachers at a school from taking part in ongoing collegial discussions. Although a longitudinal analysis is made in this article, we have made the decision to also include Emma's and Mary's voices in the analysis since they took part in the discussions. An overview of participants is presented in Table 1. All participants were qualified for science teaching for the years indicated in the table.

\subsection{Research Project and Data Collection}

The research project spanned 3 years and included 12 focus group meetings, which each lasted for $2 \mathrm{~h}$ (see Appendix for an outline of the project and focus group activities). The participation in the project was voluntary, and the teachers did not receive any compensation; all teachers were however granted permission to take part in the meetings during working hours when possible. The first author was the moderator of all focus group meetings. A fruitful way to

Table 1 Pseudonyms and particulars for teachers participating in the project

\begin{tabular}{lll}
\hline & Years in teaching $^{\mathrm{a}}$ & Teacher education aimed at school years \\
\hline Agnes & 16 & $1-7$ \\
Carolyn & 32 & $4-6$ \\
Ella & 17 & $1-7$ \\
Emma & 12 & $4-9$ \\
John & 15 & $4-9$ \\
Nina & 10 & $4-9$ \\
Mary & 8 & $1-7$ \\
\hline
\end{tabular}

${ }^{\mathrm{a}}$ At the outset of the project 
trigger discussions among the participants in a focus group is for them to have access to material with which to work during the meetings (Wibeck 2010). In this study, the participants were given working material consisting of short texts to read before the meetings (only during year one) and/or tasks to work with during meetings (see Appendix for an overview of meetings and distributed material).

The readings and discussions were based on a framework consisting of seven NOS themes (the seven themes were later reduced to five themes based on the group discussions). The NOS themes were comprehensive and broad in order to allow for multiple perspectives and a large variety of NOS issues to be included as suggested in, for example, Allchin (2011) and Erduran and Dagher (2014). They have a starting point in the NOS tenets described by Lederman (2007), but were further developed and inspired by both science education literature and science studies perspectives, as suggested in Duschl et al. (2006). The two themes, sociocultural and subjective aspects, that are central for this article are deeply intertwined (see Section 1.2) and, hence in this article, merged into one overarching theme. The themes are briefly described below (for a more detailed description see Leden et al. 2015; Leden 2017):

- The theme tentative aspects of science was concerned with continuity/change and certainty/uncertainty in relation to scientific knowledge. Both historical and contemporary examples coupled to different disciplines are of importance.

- The theme empirical aspects of science was, in addition to the significance of empirical contributions to science, broadened to include theoretical contributions and their interconnection with empirical contributions, and aspects concerned with scientific practices (c.f. Erduran and Dagher 2014). Relevant topics are, for example, the roles and relations between observations, experiments, models, and laws; trustworthiness; diversity of methods; and boundaries of science.

- The theme creative aspects of science was concerned with creativity and rationality in relation to the research process (from problem stating to interpreting observations and inventing explanations).

- The theme sociocultural and subjective aspects of science was concerned with the extent to which science is influenced by subjectivity and society/culture at different stages of the research process (Stenmark 2004). Thus, the theme deals with questions about realism versus relativism as well as questions concerning the science wars debate (see Dadachanji 1998; Mosco 2012). Both historical and contemporary contexts are important to this broad theme as well as a number of perspectives mentioned in Section 1.2 such as theory-laden/ neutral observations (Lederman 2007), economy (Irzik 2010), and politics (Allchin 2011; Erduran and Dagher 2014). Other perspectives of interest are cultural and social practices of different sciences - e.g., epistemic cultures (Knorr-Cetina 1999), and feminist theories (Freedman 2009; Longino 1990).

The readings aimed at putting forward different perspectives and were mainly built around questions that could prompt discussions. A translated excerpt from the text that was distributed before the second meeting exemplifies this:

In the pursuit to describe reality as accurately as possible objectivity becomes a question. How objective can an investigation or a research project be? Are there different parts of the research process (e.g., in problem stating, data collection, justifying claims, or application) that are more subjective than other parts? Should this be considered a problem or is it just part of science being a human activity? Some people argue that science concepts, theories, models, and laws are altogether constructed by humans and 
not given by nature. This view can be very controversial to others, who consider science as providing an accurate picture of reality as it really is. Furthermore, there are also others who discuss a balance between science as objective or science as subjective in that they regard knowledge as constructed - with different possible constructions of reality - but that reality does not provide freedom to construct whatever we want - there is a reality independent from us (which also can be discussed in connection to the previous theme). (Excerpt from focus group text).

Thus, during the project, the teachers gained experience of NOS and NOS teaching from readings, discussions, and the development and implementation of NOS activities. The longitudinal character of the project enabled us to study how the teachers' ways of talking about NOS and NOS teaching changed over time. The discussions during the focus groups developed differently. In this case, the moderator mostly prompted the teachers to talk about a couple of chosen topics and the discussion wandered freely among the participants with little interference from the moderator apart from ensuring everyone had their say. However, in a couple of meetings, where teaching examples were shown, the moderator also made suggestions and elaborations. An excerpt from one of the focus groups is provided below (Section 2.4, Table 2). The excerpt intends to illustrate the character of the discussions as well as provide an insight into the interpretation and analysis.

In focus group meetings, during the second and third years, the teachers planned NOS activities that were later implemented in their own classrooms and thereafter reflected on in the following focus group meetings (Appendix). One of the activities was highly contextualized and focused mainly on sociocultural and subjective aspects of science through students' reading and discussing of web-based information and news articles about a socio-scientific issue. In this activity, the teachers had prepared NOS questions that their students should use as a guide while reading the texts. The reading was followed by students writing an argumentative text (years 7-9) or taking part in a panel debate (years 4-6). The other activity was a black-box activity where the students encountered all of the above described aspects of science through teacher initiated group and whole-class discussions. According to previous Swedish studies, there is no tradition of NOS teaching in Sweden (e.g., Gyllenpalm et al. 2010, Högström et al. 2006). Thus, at the end of the project, even if the teachers were not experts on NOS, it can be assumed that they had gained a higher level of experience in NOS and NOS teaching than could be expected from most teachers in Sweden.

\subsection{Analysis}

This article is based on data that consists of the recorded and transcribed discussions from 12 focus group meetings. The interactions and negotiations among the participants in a focus group can be an excellent source for learning about diverging opinions, tensions, taken-forgranted patterns, and meaning-making within a certain group (Halkier 2010). The analysis is based on qualitative content analysis of the focus group transcripts (Hsieh and Shannon 2005; Kvale 1997). Initially, the transcripts were read repeatedly in order to get a sense of the whole material (c.f. Hsieh and Shannon 2005). Then, five steps were followed in order to answer the research questions.

The first three steps are related to the first research question: What suggestions concerning the teaching about sociocultural and subjective aspects of science are raised by the teachers over the years? These steps were: (1) identification of passages in the transcripts where teachers discuss the teaching of sociocultural and subjective aspects, (2) identification and categorization of specific sociocultural and subjective issues within these passages, and (3) 
Table 2 Transcript excerpt with example of analytical process

\begin{tabular}{clc} 
Transcript excerpt (coded parts in bold) & $\begin{array}{l}\text { Issues (step 2) and contexts } \\
\text { (step 3) }\end{array}$ & $\begin{array}{l}\text { Challenges and opportunities } \\
\text { (steps 4 and 5) }\end{array}$ \\
\hline $\begin{array}{c}\text { Nina: I did like this when I introduced, } \\
\text { they got four articles, two that were } \\
\text { positive and two that were negative }\end{array}$ & $\begin{array}{c}\text { Issue: values and } \\
\text { viewpoints, } \\
\text { Context: scientific practices }\end{array}$ & $\begin{array}{c}\text { Student-related opportunities: abilities } \\
\text { for discussions; understanding of } \\
\text { NOS }\end{array}$
\end{tabular}
towards energy drinks, and we read them together here in the classroom and talked about if they [the articles] were positive or negative and what they [the students] thought were positive and negative in the different articles, and then we discussed this about underlying factors and reasons for interpreting the result the way one does and there was actually someone in the class who started talking about underlying factors without me saying anything.

\section{Ella: That's great!}

Nina: [Nina talks about practical details] /.../ I feel they thought it was difficult. They do take position for and against energy drinks. Then I haven't had the time to study how they justify it or how they use the texts, but at least they have an opinion. But I experience it as if many thought it was difficult [to know] how to write and what to write, both the weak and the smart or they who [usually] think it's easy and they who think it's hard. The group is pretty weak and there are many who do not pass, so it's a pretty difficult task for them I think, yes.

John: /.../ there are many, particularly boys, who are not very interested in too much unnecessary writing, so I experienced some resistance against writing. But I also believe that it might not just be resistance against writing but rather that they actually thought it was hard, because basically we have not worked very much with this type of tasks at all, to read up on a subject, then take position, and then justify your position through information found in a text. They have tried a few much simpler tasks before. The part where they take position for or against allowing energy drinks and put forward a few arguments, the ones I have had time to read, they have managed that. The difficulties for them have been the follow-up questions, for example, who can be
Issue: economic interests that has to do with companies and organizations

Context: scientific practices
Student-related opportunities: practiced taking position (abilities for discussion, develop critical thinking/reflexivity)

Student-related challenges: reading and writing difficulties
Student-related challenge: reading and writing difficulties; NOS too abstract (difficulties with the follow-up questions); difficult to discuss/argue and take position

Structural challenge: breaks with science teaching tradition

Student-related opportunities: Practiced taking position (develop abilities for discussion, critical thinking /reflexivity) 
Table 2 (continued)

$\begin{array}{lll}\text { Transcript excerpt (coded parts in bold) } & \begin{array}{l}\text { Issues (step 2) and contexts } \\ \text { (step 3) }\end{array} & \begin{array}{l}\text { Challenges and opportunities } \\ \text { (steps } 4 \text { and 5) }\end{array}\end{array}$
interested in that this research is actually conducted, and are there different stakeholders and so forth.
Those three bullet points were meant to start you thinking and then they should be integrated in the text to further strengthen your position. But I haven't noticed anyone doing that, they have just answered them as question 1, question 2 question 3. Like totally disconnected. No one has kind of used it.
Nina: in their text?
John: In their text, and perhaps that's not so darn strange, because at least in science class we have not worked like this. This does not mean they haven't practiced it in Swedish class. Nina: They are used to having it presented as questions.

identification and categorization of contexts, general (no clear connection to science), socioscientific (science in society), and scientific practices for each issue. The last two steps are related to the second research question: What opportunities and challenges concerning the teaching about sociocultural and subjective aspects of science are emphasized over the years?

These steps were: (4) identification of challenges and opportunities that the teachers discuss in relation to teaching of the identified issues and (5) categorization of identified challenges and opportunities.

A directed content analysis (Hsieh and Shannon 2005) was used to code every occasion when teaching of sociocultural and subjective aspects of science were mentioned (step 1). Note that sociocultural and subjective aspects were only coded when they were related to teaching, and not when teachers discussed these aspects of science in a more general way. In a conventional content analysis, patterns and categories emerge from the data and no preconceived categories are used (Hsieh and Shannon 2005). This kind of analysis was used to get a more nuanced picture of how the teaching repertoire was filled with sociocultural/subjective issues during the project (steps 2 and 3). In the next step, the chosen passages were revisited and categorized as challenges and opportunities (step 4). Finally, the challenges and opportunities were analyzed and coded according to recurrent patterns in the group discussions (step 5). The coding in steps 2, 3, and 5 also made it possible to discern certain changes over the years.

In Table 2, we use an excerpt from a transcript in order to provide an insight into the character of the discussions in the focus groups and to further explain the analytical steps and coding of the transcripts. The excerpt is from the transcribed discussion of focus group 3 year 2 (see Appendix) where the teachers began by taking turns in briefly describing their experiences from the implementation of the text-based ${ }^{2}$ activity.

\footnotetext{
${ }^{2}$ Text here refers to web-based information and news articles as opposed to textbook texts that have been specifically designed for students.
} 
In the first step, passages of the transcripts were chosen for further analysis when they showed teachers' discussions on teaching sociocultural and subjective aspects of science. The passage chosen here starts with Nina's description and reflection on the implementation of a text-based activity in her grade 8 . The rest of the excerpt contains other teachers' comments on her description, as well as John's description of his experiences from the same activity.

In the second step, sociocultural and subjective NOS issues were coded and categorized. First, Nina talked about "underlying factors" without specifying what these could be. Thus, they were not categorized as a specific issue. However, she also talked about discussing "reasons for interpreting the result the way one does" which was categorized as specific viewpoints and values of the individual researcher. Later John talked "about who is interested in that this is investigated at all, and are there different groups and so forth"; this was categorized as economic interests that have to do with companies and organizations.

In the third step, all issues were scrutinized for qualitative differences based on how they are contextualized in teaching situations. Three different contexts were identified: general (no clear connection to science), socio-scientific (science in society), and scientific practices (scientific knowledge-creating practices). Both of the above issues (viewpoints and values, and economic interests) were categorized as scientific practices meaning that sociocultural and subjective factors were discussed as affecting the processes, practices, and outcomes of science.

Challenges and opportunities were identified in the fourth step and further coded as specific opportunities and challenges principally related to students, teachers, or structures (step 5). In this case, it is important to note that the opportunities were not always explicitly expressed by the teachers. Instead, they were often, by the researchers, interpreted as implicitly expressed opportunities or benefits that would follow from the teaching. As an example, students' ability to engage in (and initiate) discussions about underlying factors ("someone in the class who started talking about underlying factors without me saying anything" followed by "That's great!") was coded as student-related learning opportunities (abilities for discussions, understanding of NOS). Another student-related opportunity was that they were able to express their position which could be considered as a development of their reflexivity as well as of their abilities for discussions. Students' difficulties regarding a teaching approach that demanded reading and writing abilities was discussed in this excerpt by both Nina and John and was coded as a challenge related to the students. Other student-related challenges had to do with their difficulties to take a position, discuss, and come up with arguments (discussed by both John and Nina). John also argued that the specific NOS questions were too abstract and thus difficult for the students to grasp. That students are not used to work with this kind of tasks in science classes, and that they are more used to "have it presented as questions" was coded as structural challenges that has to do with the science teaching traditions present in these classrooms.

In the results section below, teachers' suggestions of issues as well as categories of opportunities and challenges are summarized in Tables 3 and 4 in order to provide an overview of the changes over the 3 years. The focus group discussions are exemplified by translated transcript excerpts. The analysis and presentation of focus group data needs to seek a balance that acknowledges the interaction between the individual and the group (Morgan 1997). The analysis reported here is directed towards the ongoing discussions and not based on statements made by single teachers. However, even if quotations in the results section are presented as part of a joint, ongoing discussion, pseudonyms for participants are presented when clarification is required in a dialog. The computer software NVivo was used as a tool throughout the analysis. 


\section{Results: Challenging Traditional School Science Through Sociocultural and Subjective Aspects}

In this article, we specifically focus on the teachers' discussions about sociocultural and subjective aspects as a way to challenge the black-and-white image of science that often prevails in the science classroom. During the entire study, the teachers returned to the issue of nuances in science. Yet, they argued that in the science classroom they often teach science in a black and white manner (c.f. Leden et al. 2015):

Mary: ... then we have to explain to them that we cannot deal with all the tiny details. Instead we do it black and white. There are other scales, but not at this level, not for these school years.

John: Simplified models.

Mary: Yes, absolutely, and I think it's important so they won't think this is the spoken truth, there can be nothing else, end of discussion. I think that's important, that [they know] at this level we follow this model. $(1: 2)^{3}$

Below, we present the teachers' suggestions of relevant issues and their discussions of opportunities and challenges and how these changed over 3 years.

\subsection{Teachers' Suggestions of Relevant Issues}

A task for the teachers during the entire project was to suggest concrete ways of how to put their ideas to work in the science classroom. In their discussions, the teachers focused to a great extent on the possibility to highlight "underlying factors" (i.e., sociocultural and subjective issues that are part of science in one way or another) in their science teaching. These issues were either addressed in a general way or in a more specific one. When discussed generally, the teachers, without mentioning any specific issues, argued that it would be beneficial if students could discuss "underlying factors." Several specific issues were identified, which were grouped and categorized in four overarching categories: economic interests and aims, ideologies/viewpoints/tendencies, knowledge/experiences, and social rank/status/organization of practices (specific issues and overarching categories are summarized in Table 3). These were issues and categories that according to the teachers could serve as a basis for deepening the discussions about why researchers sometimes do not agree on interpretations, or why a specific method is chosen rather than another. An example of an issue that was coded as social rank, status and reputation is Ella's description of the discussions that were part of her implementation of the black-box activity:

\footnotetext{
Ella: You know, at a certain age they have one hundred percent trust in their teacher, then they start questioning. And some pals are not trusted at all /.../ if a guy or a girl comes along who doesn't have very high status, and who often doesn't say very much, they [the others] won't listen, and they need to become aware of that.

Agnes: Although, it's really hard to discuss that. Then you will almost have to observe another group. Otherwise it becomes so revealing.

Ella: Yes, well no, you can't do that, but it's the same thing as in this discussion, but then I chose to bring it up from the perspective of a research group: Can it be like this in different research groups as well? And I brought that discussion up that in year five, and they really started discussing, you know like: well it has
}

\footnotetext{
${ }^{3}$ All quotations are marked by two numbers: the first number represents the year of the project, the second number represents the number of the focus group. Thus, 1:2 means year 1 of the project, focus group meeting two.
} 
to depend on if someone has made a clever discovery before, or if you are a famous inventor or scientist,

then it's clear that you will listen more to that person because he knows what he's talking about (3:3).

The issues presented here represent overarching suggestions that span the entire compulsory school. For a detailed description of these teachers' discussion of age-appropriate NOS teaching, see Leden and Hansson (2017).

In Table 3, it is shown that several issues were considered as suitable for teaching in compulsory school. The letter " $x$ " indicates that a certain issue was up for discussion on at least one occasion during the particular focus group. Over the years, the teachers came up with new suggestions of issues that could be dealt with in the science classroom. Thus, their teaching repertoire, with regards to sociocultural and subjective issues, expanded during the project (Table 3). This is particularly evident for the knowledge and experience category, where the different frames of reference were the only issue discussed during the first year, while in the second and third years further issues such as scientific disciplines and social background were suggested. In one exceptional case, one issue was only discussed during the first year: scientists are like ordinary people. Moreover, it is possible to discern certain "favourite" issues, such as social rank, frames of reference, values and economic interests, which the teachers chose to discuss on several occasions and during

Table 3 Teachers' suggestions of sociocultural and subjective issues relevant for science teaching

\begin{tabular}{|c|c|c|c|c|c|c|c|c|c|c|c|c|c|}
\hline \multirow[b]{3}{*}{ Category } & \multirow[b]{3}{*}{ Specific issue } & \multirow{2}{*}{\multicolumn{3}{|c|}{$\begin{array}{l}\text { Year } 1 \\
\text { Focus } \\
\text { group }\end{array}$}} & \multicolumn{4}{|c|}{ Year 2} & \multicolumn{5}{|c|}{ Year 3} \\
\hline & & & & & \multicolumn{4}{|c|}{$\begin{array}{l}\text { Focus } \\
\text { group }\end{array}$} & \multicolumn{5}{|c|}{ Focus group } \\
\hline & & 1 & 2 & 3 & 1 & 2 & 3 & 4 & 1 & 2 & 3 & 4 & 5 \\
\hline \multirow[t]{3}{*}{ Economic interests and aims } & $\begin{array}{l}\text { Related to companies and } \\
\text { organizations }\end{array}$ & & $\mathrm{x}$ & $\mathrm{x}$ & & $\mathrm{x}$ & $\mathrm{x}$ & $\mathrm{x}$ & & $\mathrm{x}$ & $\mathrm{x}$ & $\mathrm{x}$ & $\mathrm{x}$ \\
\hline & $\begin{array}{l}\text { Investigations bought for certain } \\
\text { purposes }\end{array}$ & & & & & & $\mathrm{x}$ & $\mathrm{x}$ & & $\mathrm{x}$ & & & \\
\hline & Related to different parts of the world & & & & & & & & & $\mathrm{x}$ & & & \\
\hline \multirow{8}{*}{$\begin{array}{l}\text { Ideologies, viewpoints, } \\
\text { tendencies }\end{array}$} & Values and viewpoints & $\mathrm{x}$ & $\mathrm{x}$ & & $\mathrm{x}$ & $\mathrm{x}$ & $\mathrm{x}$ & $\mathrm{x}$ & & $\mathrm{x}$ & $\mathrm{x}$ & $\mathrm{x}$ & \\
\hline & Differences due to different times & $\mathrm{x}$ & & & $\mathrm{x}$ & & & $\mathrm{x}$ & & & $\mathrm{x}$ & $\mathrm{x}$ & \\
\hline & Worldviews & $\mathrm{x}$ & & & & & & & & & $\mathrm{x}$ & & \\
\hline & $\begin{array}{l}\text { Political interests, decisions and } \\
\text { regulations }\end{array}$ & & $\mathrm{x}$ & $\mathrm{x}$ & & $\mathrm{x}$ & & & & & & & \\
\hline & Differences due to different religions & & & $\mathrm{x}$ & $\mathrm{x}$ & & & & & & & $\mathrm{x}$ & \\
\hline & Differences due to different cultures & & & $\mathrm{x}$ & & $\mathrm{x}$ & $\mathrm{x}$ & & & & $\mathrm{x}$ & & $\mathrm{x}$ \\
\hline & Societal trends & & & $\mathrm{x}$ & & & & $\mathrm{x}$ & $\mathrm{x}$ & $\mathrm{x}$ & & & \\
\hline & $\begin{array}{l}\text { Western and non-western countries: } \\
\text { differences }\end{array}$ & & & $\mathrm{x}$ & $\mathrm{x}$ & & & & $\mathrm{x}$ & $\mathrm{x}$ & & & \\
\hline \multirow[t]{5}{*}{ Knowledge and experience } & Different frames of reference & $\mathrm{x}$ & $\mathrm{x}$ & & & $\mathrm{x}$ & & $\mathrm{x}$ & $\mathrm{x}$ & & $\mathrm{x}$ & $\mathrm{x}$ & \\
\hline & Social backgrounds & & $\mathrm{x}$ & & & & & & $\mathrm{x}$ & $\mathrm{x}$ & & & \\
\hline & Prevailing theories & & $\mathrm{x}$ & & $\mathrm{x}$ & $\mathrm{x}$ & $\mathrm{x}$ & $\mathrm{x}$ & $\mathrm{x}$ & $\mathrm{x}$ & & & \\
\hline & Different scientific disciplines & & & $\mathrm{x}$ & $\mathrm{x}$ & & & & $\mathrm{x}$ & $\mathrm{x}$ & & & \\
\hline & Bias/prejudice & & & $\mathrm{x}$ & & & & $\mathrm{x}$ & $\mathrm{x}$ & $\mathrm{x}$ & & & \\
\hline \multirow[t]{4}{*}{$\begin{array}{l}\text { Social rank/status/organization of } \\
\text { practices }\end{array}$} & $\begin{array}{l}\text { Critical review of results, critical } \\
\text { thinking }\end{array}$ & $\mathrm{x}$ & $\mathrm{x}$ & & $\mathrm{x}$ & & $\mathrm{x}$ & & & $\mathrm{x}$ & $\mathrm{x}$ & & \\
\hline & Social rank, status and reputation & $\mathrm{x}$ & $\mathrm{x}$ & & & $\mathrm{x}$ & $\mathrm{x}$ & $\mathrm{x}$ & $\mathrm{x}$ & $\mathrm{x}$ & $\mathrm{x}$ & & $\mathrm{x}$ \\
\hline & Scientists are like ordinary people & & $\mathrm{x}$ & & & & & & & & & & \\
\hline & $\begin{array}{l}\text { Organization of } \\
\text { knowledge-producing practices }\end{array}$ & & & & $\mathrm{x}$ & & $\mathrm{x}$ & $\mathrm{x}$ & $\mathrm{x}$ & $\mathrm{x}$ & $\mathrm{x}$ & & \\
\hline
\end{tabular}


the entire project as shown in Table 3. This table further shows that some focus groups had a tendency to produce more issues than others, for instance, focus group 3:3 which is exceptional in that way. During this focus group, the teachers owned most part of the discussion and specific reading material or teaching examples were not provided by the researcher on these occasions (see Appendix).

\subsubsection{Connecting Sociocultural and Subjective Issues to Different Contexts}

Teachers' ways of suggesting how the specific issues ought to be included in science class changed dramatically between year one and year two (see Fig. 1). However, no major changes appeared between years two and three. Figure 1 presents the proportions of how these different approaches were discussed during the 3 years in relation to all categories presented in Table 3 . The three quotations below serve to exemplify the different ways of including sociocultural and subjective issues in the science classroom. For clarity, they have all been chosen from the same category ideologies, viewpoint and tendencies (see Table 3).

During the first year, the teachers more often talked about sociocultural and subjective issues in general and imprecise ways which indicated that these issues had no clear connection to science. Using a general way of speaking was a way of trying to get to grips with how to include such issues in the science teaching. This is exemplified in the quotation below where the teachers have been asked by the moderator to discuss how subjective aspects could be included in science teaching:

Ella: You can take a simple thing like their [the students'] conflicts. The exact same thing has happened and both of you were there but you experience it totally differently.

Moderator: It can kind of be connected to an everyday context?

Ella: They are very aware of that.

Mary: But then I believe that it can be different to include it. They are aware of it in everyday situations and such, but then I think it can be difficult to make them think about why it is like that in science as well:

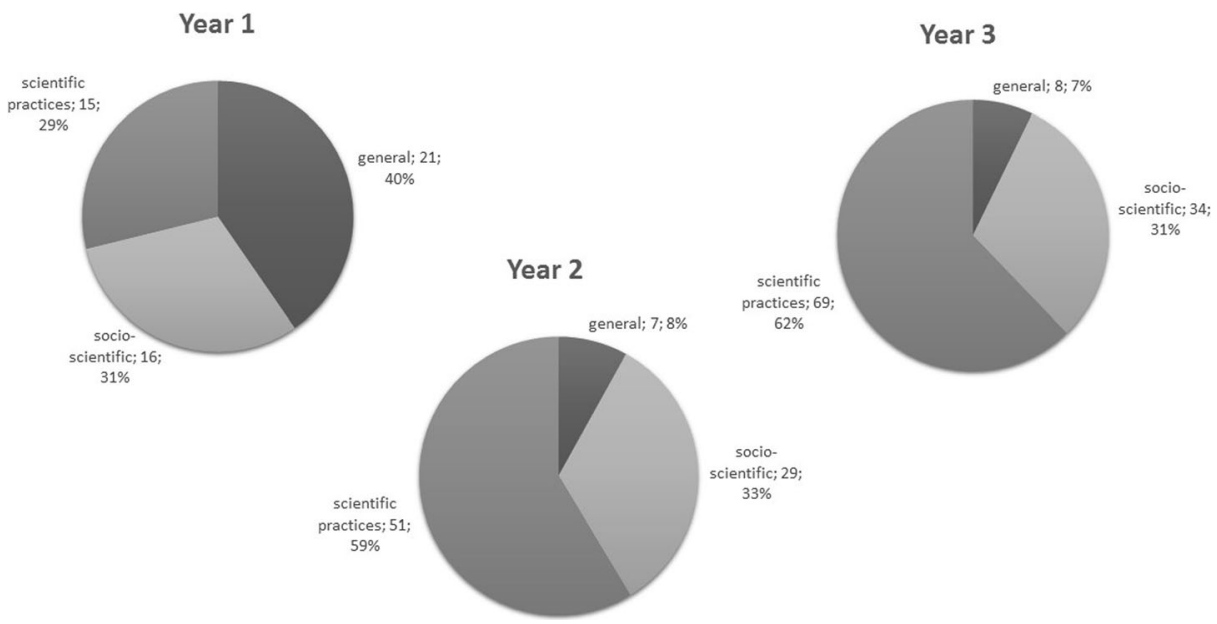

Fig. 1 Number and percentage of issues categorized as connected to general, socio-scientific, or scientific practices contexts during the projects 
they are scientists, they are supposed to be objective and so on. They can't really see that it's the same thing. (1:2)

However, as the project proceeded, the teachers' suggestions became more concretely connected to science, either through socio-scientific issues or through references directly to scientific practices (see Fig. 1). Quotations like: "[You can address sociocultural issues] maybe a little bit in sex education /.../ that you have different views on things in different parts of the world. (1:3)" were categorized as Socio-scientific, meaning that sociocultural and subjective aspects were discussed in connection to science in society through decisions, position taking, and applications (e.g., socio-scientific issues). Other quotations, like the example below, were categorized as Scientific practices, meaning that sociocultural and subjective aspects were discussed in connection to how scientific knowledge-creating practices (i.e., problem stating, planning investigations, conducting investigations, interpreting results, communicating results) are affected:

Nina: It can be when you [the student] are about to plan your lab-work or even when you are about to draw conclusions and [they discuss] the underlying factors, that you can think differently depending on which culture you are from [coded as differences due to different cultures, Table 3]. And who says what that you might trust people differently depending on who they are [coded as social rank, status, and reputation, Table 3]. (3:5)

\subsection{Opportunities and Challenges Over the Years}

A large portion of the discussions during the project came to deal with the challenges and opportunities that teachers anticipated or experienced in relation to teaching about sociocultural and subjective aspects of science. In focus groups 1:2, 1:3, 2:3, 3:1, and $3: 2$, the moderator specifically asked the teachers to discuss what they had experienced as, or what they thought might be, challenges and opportunities. However, opportunities and challenges were natural topics also in the other focus groups. The opportunities and challenges that were discussed over the years are presented below and also summarized in Table 4. In the analysis, opportunities and challenges were categorized as either related to person (students or teachers) or to structure. Furthermore, broad subcategories were organized by the researchers. For instance, the category increased engagement and interest comprised a variety of statements related to students such as engagement in discussions, enjoyment, and pride due to being able to master a difficult task. This broad categorization is visible in Table 4. As in Table 3, the letter " $x$ " indicates that the subcategory was up for discussion at least once during the particular focus group meeting.

\subsubsection{Opportunities and Challenges Discussed During the First Year of the Project}

During the first year of the project, the main opportunities that the teachers discussed were that teaching about the sociocultural and subjective aspects of science could provide a way for students to get to grips with the idea that science is not just black and white. This is connected to the opportunity of meeting curricular demands on science teaching as something more than the teaching of facts (Table 4, Embraces teaching goals other than facts) which these teachers described as a more prominent feature in the latest curriculum: 
Table 4 Challenges and opportunities connected to teaching about sociocultural and subjective aspects

\begin{tabular}{|c|c|c|c|c|c|c|c|c|c|c|c|c|c|}
\hline \multirow[b]{3}{*}{ Category } & \multirow[b]{3}{*}{ Sub-category } & \multirow{2}{*}{\multicolumn{3}{|c|}{$\begin{array}{l}\text { Year } 1 \\
\text { Focus group }\end{array}$}} & \multirow{2}{*}{\multicolumn{4}{|c|}{$\begin{array}{l}\text { Year } 2 \\
\text { Focus group }\end{array}$}} & \multicolumn{5}{|c|}{ Year 3} \\
\hline & & & & & & & & & \multicolumn{5}{|c|}{ Focus group } \\
\hline & & 1 & 2 & 3 & 1 & 2 & 3 & 4 & 1 & 2 & 3 & 4 & 5 \\
\hline \multicolumn{14}{|l|}{ Opportunities } \\
\hline \multirow[t]{7}{*}{ Students } & Understanding of nuances & & $\mathrm{x}$ & & $\mathrm{x}$ & $\mathrm{x}$ & $\mathrm{x}$ & $\mathrm{x}$ & & $\mathrm{x}$ & $\mathrm{x}$ & & $\mathrm{x}$ \\
\hline & Enhanced understanding of science and NOS & & $\mathrm{x}$ & & $\mathrm{x}$ & & $\mathrm{x}$ & & & $\mathrm{x}$ & & $\mathrm{x}$ & $\mathrm{x}$ \\
\hline & Development of critical thinking/reflexivity & & & & $\mathrm{x}$ & $\mathrm{x}$ & $\mathrm{x}$ & & $\mathrm{x}$ & $\mathrm{x}$ & & $\mathrm{x}$ & $\mathrm{x}$ \\
\hline & Increased engagement and interest & & & & $\mathrm{x}$ & $\mathrm{x}$ & $\mathrm{x}$ & & & $\mathrm{x}$ & $\mathrm{x}$ & $\mathrm{x}$ & $\mathrm{x}$ \\
\hline & Increased participation/inclusion & & & & & & $\mathrm{x}$ & $\mathrm{x}$ & $\mathrm{x}$ & $\mathrm{x}$ & & & $\mathrm{x}$ \\
\hline & Increased ability for discussions & & & & & & $\mathrm{x}$ & & $\mathrm{x}$ & $\mathrm{x}$ & & $\mathrm{x}$ & $\mathrm{x}$ \\
\hline & Ability to deal with science content in media & & & & $\mathrm{x}$ & $\mathrm{x}$ & $\mathrm{x}$ & & & & $\mathrm{x}$ & $\mathrm{x}$ & $\mathrm{x}$ \\
\hline \multirow[t]{2}{*}{ Teachers } & Inspiring and fun & & & & $\mathrm{x}$ & $\mathrm{x}$ & $\mathrm{x}$ & $\mathrm{x}$ & & $\mathrm{x}$ & & & $\mathrm{x}$ \\
\hline & Increased status as a teacher & & & & & $\mathrm{x}$ & $\mathrm{x}$ & & & & & & \\
\hline \multirow[t]{4}{*}{ Structures } & Embraces teaching goals other than facts & $\mathrm{x}$ & & & $\mathrm{x}$ & $\mathrm{x}$ & $\mathrm{x}$ & $\mathrm{x}$ & $\mathrm{x}$ & $\mathrm{x}$ & $\mathrm{x}$ & & $\mathrm{x}$ \\
\hline & Interdisciplinary & & & & $\mathrm{x}$ & $\mathrm{x}$ & $\mathrm{x}$ & & & & & & \\
\hline & Developing teaching practice & & & & & & $\mathrm{x}$ & $\mathrm{x}$ & & $\mathrm{x}$ & & & $\mathrm{x}$ \\
\hline & Science becomes connected to reality & & & & & & & & & & $\mathrm{x}$ & & \\
\hline \multicolumn{14}{|l|}{ Challenges } \\
\hline \multirow[t]{5}{*}{ Students } & Dislikes uncertainty & & $\mathrm{x}$ & & $\mathrm{x}$ & & $\mathrm{x}$ & $\mathrm{x}$ & & $\mathrm{x}$ & $\mathrm{x}$ & $\mathrm{x}$ & \\
\hline & Difficult to discuss/argue & & $\mathrm{x}$ & & $\mathrm{x}$ & $\mathrm{x}$ & $\mathrm{x}$ & $\mathrm{x}$ & $\mathrm{x}$ & $\mathrm{x}$ & & $\mathrm{x}$ & \\
\hline & Too abstract for younger students & & & $\mathrm{x}$ & & $\mathrm{x}$ & & & $\mathrm{x}$ & & $\mathrm{x}$ & & \\
\hline & Too abstract for all students & & & $\mathrm{x}$ & & & $\mathrm{x}$ & & & $\mathrm{x}$ & & & \\
\hline & Reading and writing difficulties & & & & $\mathrm{x}$ & $\mathrm{x}$ & $\mathrm{x}$ & & & $\mathrm{x}$ & & & \\
\hline \multirow[t]{6}{*}{ Teachers } & Lacking knowledge about NOS teaching & $\mathrm{x}$ & $\mathrm{x}$ & $\mathrm{x}$ & $\mathrm{x}$ & $\mathrm{x}$ & & & & $\mathrm{x}$ & $\mathrm{x}$ & $\mathrm{x}$ & \\
\hline & Lacking knowledge about NOS & $\mathrm{x}$ & & $\mathrm{x}$ & $\mathrm{x}$ & $\mathrm{x}$ & & $\mathrm{x}$ & & & & & \\
\hline & Hard to find suitable topics & & & $\mathrm{x}$ & $\mathrm{x}$ & $\mathrm{x}$ & & $\mathrm{x}$ & & $\mathrm{x}$ & $\mathrm{x}$ & & \\
\hline & Insecurity and fear of failure & & & & $\mathrm{x}$ & $\mathrm{x}$ & $\mathrm{x}$ & & & $\mathrm{x}$ & $\mathrm{x}$ & & \\
\hline & Planning is hard and time consuming & & & & & $\mathrm{x}$ & & $\mathrm{x}$ & & $\mathrm{x}$ & & & $\mathrm{x}$ \\
\hline & Lacking knowledge about assessment & & & & & $\mathrm{x}$ & $\mathrm{x}$ & $\mathrm{x}$ & & $\mathrm{x}$ & & & \\
\hline \multirow[t]{5}{*}{ Structures } & Breaks with science teaching traditions & $\mathrm{x}$ & & $\mathrm{x}$ & & $\mathrm{x}$ & $\mathrm{x}$ & $\mathrm{x}$ & & $\mathrm{x}$ & & & $\mathrm{x}$ \\
\hline & Time consuming, less time for other content & & & & $\mathrm{x}$ & $\mathrm{x}$ & $\mathrm{x}$ & $\mathrm{x}$ & $\mathrm{x}$ & $\mathrm{x}$ & $\mathrm{x}$ & & \\
\hline & Expectations from parents and colleagues & & & & $\mathrm{x}$ & & & & & & & & $\mathrm{X}$ \\
\hline & Messy classroom, technical difficulties & & & & & & $\mathrm{x}$ & & & $\mathrm{x}$ & & & \\
\hline & Resource consuming (e.g., smaller groups) & & & & & $\mathrm{x}$ & $\mathrm{x}$ & & & $\mathrm{x}$ & & $\mathrm{x}$ & \\
\hline
\end{tabular}

Carolyn: It is not enough knowing everything about the photosynthesis... it is much clearer now [in the curriculum] what is expected.

John: Not so much memorization, cramming and repeating, but instead you can do a lot of other stuff

Carolyn: and that is connected to the things we talk about here, views [in science] and what that is and critical thinking and source criticism and all that. (1:1)

The challenges discussed during the first year (summarized in Table 4) had to do with the assumption that students would have difficulties thinking of science as something more than concepts, and that they would get worried if the black and white picture of science was disrupted. In the excerpt below (focus group 1:2), the moderator has just reconnected to a previous discussion among the teachers about conflicting evidence and has asked what would happen if conflicts were avoided and science was taught in a black and white fashion: 
Ella: I guess that would be very convenient.

Moderator: um

Carolyn: Yes!

Ella: because then you won't have to wrestle with those thoughts

Carolyn: But things aren’t only black and white! So I don't know but

Mary: I think it matters on what level the students are and not just age level but

Ella: No

Mary: We should not think in relation to grading, but they who have a more developed, well, they have gotten further, while for some students who almost cannot pass, for them it would probably, like you say, be rather convenient and kind of like: now we know how it is, it feels safe... (1:2)

The quotation further shows that the teachers argued that sociocultural and subjective aspects are abstract and thus would be difficult for many students to grasp. Also, teaching formats, in which students would have to take initiative in discussions, were considered a possible challenge. Furthermore, the teachers expressed that they themselves struggled to get to grips with understanding the sociocultural and subjective aspects as well as understanding how to teach about these aspects in the science classroom (Table 4, Lacking knowledge about NOS teaching; Lacking knowledge about NOS). There was also some confusion regarding whether or not sociocultural and subjective issues could be considered to be proper science (Table 4, Breaks with science teaching traditions).

\subsubsection{Opportunities and Challenges Discussed During the Second and Third Years of the Project}

There is a considerable change in the amount of opportunities and challenges discussed by the teachers after the first year (see Table 4). The opportunities that were described during year 1 remained, but more opportunities were added at the beginning of year 2 , when the teachers were presented with teaching examples and started planning their own activities. This meant that at the beginning of year 2 the teachers talked about expected opportunities such as increased engagement and the development of critical thinking and reflexivity (Table 4). After implementing the activities, the teachers argued that concrete gains, such as the development of abilities for argumentation and increased participation among students, were achieved (see Table 4):

There was an incredible lot of discussing going on in grade 6 about how it actually works regarding if science can be ordered [for certain purposes]; which research reports that are published; and the results from them, if they can be trusted or not. And that discussion, I think it was really rewarding, they [the students] became more critical.

Moderator: Okay, it awoke that kind of thoughts

Ella: Yes, it did and I thought it was awesome to see that there were so many, and so many who are otherwise often silent, that were thinking, raising their hands and engaging. So, I thought that was pretty cool (3:2) 
The expectations of, for example, increased interest and engagement were also met as seen in the quotation below where one teacher tells the focus group of her experience of engagement (Table 4) among her students (see also Table 3 Critical review of results, critical thinking; Organization of knowledge-producing practices):

Carolyn: One of my students said at lunch time: 'But who checks that the ones who do research have done it right?' And I said that if you are a researcher you have a result and then you have to answer for it to other scientists. 'But isn't there someone kind of superior who can tell that: No, there you have researched wrong!'. They [the students] are so used to handing in things that get assessed you know, but I said that they [the scientists] have to present their work maybe to get a certain job, or for other researchers to review it/.../ That was an interesting thought among them.

Moderator: Absolutely.

Carolyn: That's how they went on, these wonderings, from the morning [when the science lesson took place] right up till lunch time.

Ella: It has started many thoughts! (2:3)

After having tried the NOS activities, the teachers also talked about experiences of emotional benefits such as the teaching being inspiring, fun, and thought-provoking, not only for the students, but also for the teachers themselves. A couple of teachers even reported that they had gotten positive feedback from parents and students, and thus felt that their own status as teachers had increased. First and foremost, however, during years 2 and 3, the opportunity of steering the teaching away from only teaching facts became more clearly articulated through discussions about possibilities to attend to all curricular goals such as source criticism and communicative skills. These goals were, according to the teachers, previously often forgotten and therefore NOS teaching was welcomed as a much-needed way to approach them. Similarly to the opportunities, the challenges also remained, and more were added throughout the project as the teachers put their ideas to work. One of these challenges was the students being uncomfortable due to the lack of right answers:

Carolyn: [when not being provided with right answers] they get totally confused and they almost become angry

Emma: They don't like uncertainty (3:3)

However, this is exactly what the teachers were striving to challenge by teaching sociocultural and subjective aspects of science in their classrooms. Thus, in the continuation of this quotation, we can sense that this challenge is turning into one of the overarching opportunities of teaching sociocultural and subjective aspects in the first place: "No, they don't [like uncertainty]. That's what I'm trying to make them get used to" (Carolyn, 3:3).

New challenges were also added that were connected to the concrete teaching situations. These could be challenges connected to students' reading and writing abilities (Table 4) or challenges connected to the teachers' limited time for planning new activities. 
The activities became time consuming both as regards the time spent on finding interesting topics/developing the activity and the time spent on the task in the classrooms. Much of this is time that is, according to the teachers, traditionally spent on teaching facts. However, as we have seen, the teachers in this study had a somewhat ambivalent relationship to the teaching of facts. Furthermore, during the second and third years, their identities as experienced science teachers were greatly challenged when they had to try activities in their classrooms that made them feel that they had less control than usual. Their classrooms were messier and nosier; some teachers were insecure in their roles as discussion leaders, and as persons who no longer provided immediate answers - they did not feel like real science teachers anymore (Table 4 breaks with science teaching traditions). In the excerpt below, John shares his experiences from working with news articles where his students were supposed to write a text that included a discussion of sociocultural and subjective issues:

John: This was the first time that I know of, where they [the students] found themselves in this situation, but they might have practiced it a little in Swedish class. And when I was sitting here about to assess this task, I felt that I myself was on shaky grounds and felt, heck, how much Swedish teacher am I supposed to be.

Ella: Yes, that too yes.

John: Then this almost felt like too much and that it became more of a task for Swedish class than a science task. And then you start wondering: well, am I old fashioned to think it should be more science or has the character of the subject changed and I haven't really been able to keep up $(2: 3)$

Moreover, as we see in the quotation above, the insecurity regarding the teaching of sociocultural and subjective aspects also included the assessment of students' knowledge. However, similarly to the earlier example regarding uncertainty, the assessment was discussed as something that could be turned into an opportunity through becoming an important way to provide more weight to NOS teaching.

\subsection{Summarizing the Results}

In summary, the results related to the first research question show that: (a) the number of suggested issues increased over the years and (b) teachers' ways of talking about issues changed from general and unprecise to more tightly connected to socioscientific or scientific contexts. The results related to the second research question show that: (a) the number of opportunities and challenges increased over the years and (b) there were tensions and intertwinements between some of the opportunities and challenges in a way that made some of the discussed challenges also be exactly what the teachers were striving to achieve (e.g., the discussion regarding students' abilities to deal with the lack of right answers).

In relation to both research questions, the most evident increases and changes occurred from the beginning of year 2 when the focus group discussions became more closely connected to teaching activities. The concrete experiences from planning (and implementing) NOS teaching intended for particular groups of students might have contributed to the teachers increased awareness and knowledge of specific opportunities and challenges. Setting aside time for NOS teaching forces you to, for instance, plan for learning opportunities and foresee and handle challenges. 


\section{Discussion}

The teaching of NOS has been a major focus in science education research for the past couple of decades (Lederman 2007). Challenges connected to NOS teaching have been thoroughly investigated and has contributed explanations as to why there is a perceived gap between research intentions and classroom practice (e.g., Abd-El-Khalick et al. 1998; Akerson and Hanuscin 2007; Brickhouse and Bodner 1992; Clough and Olson 2012; Lakin and Wellington 1994; Hodson 1993; Höttecke and Silva 2011; Leden et al. 2015; Lederman 1995). In other articles (Leden et al. 2015; Leden and Hansson 2017), we have reported on, and argued that, teachers' perspectives constitute an important part in the attempt to understand and examine this gap further. In the present study, we continue our exploration of teachers' perspectives. This article adds to previous research with longitudinal research on teachers' suggestions of sociocultural and subjective NOS issues, and reports on their perspectives on both opportunities and challenges that follow from teaching the suggested issues. Moreover, the longitudinal approach contributes with insights into how perspectives and suggestions can change over time when teachers take part in reflective discussions about NOS and NOS teaching. These results are useful in the development of NOS courses for teacher education and professional development.

\subsection{Longitudinal Exploration of Issues, Opportunities, and Challenges}

Despite earlier reports on difficulties connected to teaching about sociocultural and subjective aspects (Akerson et al. 2011; Leden et al. 2015), the present study reports on an increasing number of issues that were suggested by the teachers as possible and meaningful to address in compulsory school science teaching. From the number of issues presented in Table 3, it is clear that many of the sociocultural and subjective issues that have been suggested by researchers in previous studies (e.g., Abd-El-Khalick 2012; Allchin 2011, Erduran and Dagher 2014; Hodson and Wong 2014; Lederman 2007) were also suggested by the teachers in the present study. Many issues were suggested already during year 1 . However, from the increase in issues during years 2 and 3, we argue that teachers' reflective discussions as well as the connection to concrete teaching situations are of great relevance.

During the project years, the way that the issues were talked about changed character, and they became more concrete in relation to scientific processes and contexts. This could be the result of the teachers' work in trying to find ways for how to include the issues in their own teaching. The practical connection to teaching resulted in suggestions that, to an increasing extent, connected the suggested issues to socio-scientific or science-practice contexts. Especially the connection to scientific practices became more pronounced after the first year-issues were suggested that could create a deeper understanding of how all parts of the research process are affected by sociocultural and subjective aspects. Thus, the sociocultural and subjective issues presented in this study constitute an important example of teachers' suggestions of how a more nuanced picture of science and its processes, results, and applications can be presented to their students.

Similarly to the suggested issues, opportunities and challenges increased over the years and became more concretely connected to the teaching situations. However, opportunities and challenges that were discussed at the beginning of the project continued to be part of the discussions until the end of the project. Many of the discussed challenges are recognizable from earlier studies on NOS such as students' abilities for abstract thinking (Abd-El-Khalick et al. 1998; Aikenhead 2006; Brickhouse and Bodner 1992; Hodson 1993; Lederman 1995; Leden 
et al. 2015) and NOS stealing time from the teaching of science concepts (Abd-El-Khalick et al. 1998; Clough and Olson 2012; Höttecke and Silva 2011). Thus, prevailing, as well as added, challenges and opportunities existed in parallel throughout the project (see Table 4).

However, teachers' awareness of opportunities, or "utility values" is imperative if NOS teaching is to become a reality in the science classrooms (Herman et al. 2015). When studying the opportunities that are discussed by the teachers in the present study (Table 4), it could be said that a large part deals with the teaching of sociocultural and subjective aspects as a means to (a) reach other, more overarching, goals of science teaching such as the development of critical scientific literacy through, for example, developing the ability to evaluate trustworthiness and critically examine investigations described in media; and (b), implicitly following from the above, to foster students' confidence in dealing with complex and nuanced questions with lack of exact answers. In Table 4, this can be seen as opportunities related to students' understanding of nuances, development of critical thinking, reflexivity, ability to take part in discussions, and to deal with science in media. These opportunities mean that the teachers, even though perceived challenging, considered sociocultural and subjective issues as part of a critical or functional scientific literacy that can be useful in everyday life as suggested in Allchin (2011), Hodson and Wong (2014), and Feinstein (2011).Thus, the goals of teaching sociocultural and subjective aspects do not seem to be so much about enhancing the understanding of NOS for its own sake, but rather NOS as a means to reach other, more far-reaching goals.

\subsection{Tensions and Parallel Tracks}

Both the challenges and the opportunities that are described in the results section bear witness of NOS teaching as something that is perceived as different from traditional science teaching. To teach about sociocultural and subjective aspects of NOS, at least through the issues that these teachers suggest, means to challenge that tradition for better or worse. A common part of the school-science tradition, as described both in the research literature (e.g., Allchin 2003; Feinstein et al. 2013; McComas 1998; Rudolph 2005; Ruhrig and Höttecke 2015; Zacharia and Barton 2004) and by the teachers in this study, is the focus on science concepts. These concepts, which are often presented as indisputable facts, constitute an important part of what is referred to as black and white science in the present study. The emphasis on black and white science runs like a silver thread throughout the project through, for example, the continuous concerns for not having enough time to teach all the facts/concepts that are presented in the curriculum. Meanwhile, gray scales run on parallel tracks, constantly challenging and blurring the black and white images. These parallel tracks create interesting tensions in the teachers' discussions of challenges and opportunities connected to the teaching of sociocultural and subjective aspects of science.

One of the tensions in the material is the ongoing implicit discussion of what science teaching is supposed to be, and lead to, and how goals can be reached. Can the desired knowledge be obtained through learning "hard facts" or should it be learned through taking part in discussions about scientific practices or socio-scientific issues debated in media or is a combination the best solution (c.f. Feinstein et al. 2013)? This eventually comes down to discussions about the goals of the science curriculum and the possibilities of meeting all goals. Another tension, which is in part intertwined with the above, is the time factor. The teaching of sociocultural and subjective aspects takes, and should according to the teachers take, a great deal of time in order to become meaningful. It takes time to plan and implement it in the classroom, and all this expenditure of time reduces the time spent on facts. It is possible that the way teachers connected the suggested issues to science practices, to an increasing extent, 
during the project (see Fig. 1), not only is a result of becoming more concrete in their suggestions, but also is a way to try to solve this tension. That is, the tighter the specific issues become connected to science the more science-like the teaching can become. Furthermore, through connecting the sociocultural and subjective issues to science content, the feeling that the facts are put on hold might be reduced. This could also create more possibilities for the teachers to get used to teaching about sociocultural and subjective aspects, as well as about other NOS aspects, on the spur of the moment in connection to whatever science content that is the topic of the lesson. Developing the abilities for teaching NOS on the spur of the moment is thought to be an important factor in making a more nuanced science part of everyday teaching practices (Herman et al. 2013; Hansson and Leden 2016).

As previously mentioned, the challenges discussed by the teachers at the beginning of the project prevailed, and more were added along the way; however, this trend applies also to the opportunities. The discussed opportunities could become very important keys in scaffolding the efforts of changing traditional science teaching. As teachers experience the engagement and participation of their students in combination with the satisfaction of developing their own practice, and the possibilities to reach more overarching goals, it might just become worth the effort.

\subsection{Implications and Concluding Remarks}

It is fairly possible that the challenges of teaching complex topics, such as the ones discussed in this article, through complex teaching approaches, like discussions and argumentation, might never disappear - after all, teaching in compulsory school is in itself a very complex task where teachers meet different student groups with different backgrounds, abilities, values, and wishes. However, teacher education has to be aware of, and take these challenges seriously. The present article shows how immensely important it is that teachers get the opportunity to plan and implement new teaching approaches. In this way, vague ideas about topics, issues, and approaches necessarily turn into concrete, and hopefully, teachable issues and practical plans. Through implementing the activities, teachers get firsthand experiences of challenges and opportunities, which makes it possible to deal with these through reflections and collaboration with other teachers, teacher students, and science educators. The experiences could also lead to the challenging of teachers' own preconceptions of, for example, students' abilities for handling abstract topics. As we saw in this study, many students took an active part in the discussions, even those that the teachers had not expected to take part.

Moreover, in combination with firsthand experiences, there ought to be a never-ending discussion on what and whom compulsory school science is for, and how meaningful teaching can be accomplished for the intended group. The discussions that the teachers in this study took part in connected both to anticipated and experienced challenges. The dynamics of the group discussions brought tensions and diverging meanings out in the open. Such discussions can create an urge and curiosity to take on the challenges. Another way to create a notion that it might be worth taking on the challenge is to take advantage of the opportunities, as the ones presented in this article as well as "success stories" (Leden and Hansson forthcoming), and use them as examples in teacher education and professional development courses. This provides insight into opportunities through practicing teachers own voices and can be combined with ideas for how to meet the challenges. Furthermore, firsthand experiences of NOS teaching in combination with teaching examples (e.g., from "success stories" or from the rich source of instructional material c.f. Allchin 2012; Clough 2011; Henke and Höttecke 2015) could constitute the basis of a broader and more solid teaching repertoire. 
This article has followed a line of research in which teachers' voices are taken seriously. The results add to the understanding of how the actual planning and implementation of NOS activities in combination with reflective discussions can become important catalysts in making discussions of NOS teaching, in this case the teaching of sociocultural and subjective aspects of science, more concrete both as regards the suggestion of relevant issues, and the discussion of opportunities and challenges. As teachers are important keys to what takes place in the classroom, their perspectives provide important information that has to be taken into consideration both in teacher education and in future science education research. Without insights into their perspectives on what is possible and valuable to do in the science classroom, the gap between the aspirations from science education research and the everyday teaching practice is not likely to be bridged.

An important lesson from this study is that no matter how willing the teachers are to teach indisputable facts from time to time, NOS is seldom suggested as facts for its own sake but rather as issues for discussion. Hence, when they suggest teaching about nuances of science (sociocultural and subjective aspects), it is by no means intended as a way to teach facts about these nuances, but instead the nuances are welcomed as a means to reach other, overarching, goals of science education. Thus, based on the results from this study, teacher education courses set on teaching NOS to future teachers should consider to contextualize much of the NOS teaching in situations both outside and within science, and above all, discussions should be initiated regarding how NOS can become a fruitful element in teaching towards scientific literacy for all.

\section{Compliance with ethical standards}

Conflict of Interest The authors have no conflict of interest to declare.

\section{Appendix}

Table 5 Description focus group activities and material

Meeting
(year/group)

$1: 1$

Introduction

- Participant presentation

- Reflections on pre-distributed text

- Participants explore the national curriculum for references to NOS (NOS references are marked and debated). Discussion on how the marked passages become visible in teaching Distributed material:

- Pre-distributed text (introduction to NOS) ${ }^{\mathrm{a}}$

- Overview of goals in national curriculum

Tentative, empirical, subjective aspects of science

- Participants' reflections on pre-distributed text with regards to both NOS in general and NOS teaching (what, how, when, for whom?)

- Discussion about NOS teaching that can be appropriate for different school years

- Participants take part in a card game (Cobern and Loving 1998) where they are prompted to take position regarding statements about science. Each person gets three envelopes marked with "agree," disagree," and "uncertain." One card at a time is distributed. Participants 
Table 5 (continued)

Meeting Summary description and distributed material
(year/group)

discuss and debate the statement on the card - consensus is not the goal. Each participant place the card in the envelope of their choice. The envelopes are collected after the meeting Distributed material:

- Pre-distributed text with questions and examples from tentative, empirical, and subjective aspects of science

- Table with school years and themes for participants' documentation

- 20 cards (adapted from Cobern and Loving 1998)

Creativity, sociocultural contexts in science, observation /inferences, theories/laws/models

- Same approach as in meeting 1:2 directed towards new themes

- Joint planning of second year of the project

Distributed material:

- Pre-distributed text with questions and examples dealing with creativity, sociocultural contexts in science, observation /inferences, theories/laws/models

- 16 cards (adapted from Cobern and Loving 1998)

Teaching examples

- Summary of discussions from year 1

- Three examples of NOS activities are distributed and demonstrated by the moderator (see distributed material below)

- Participants discuss for each example: (a) what aspects of NOS are visible in the examples, (b) which aspects could be made visible in the science classroom, (c) how?/for whom?

- Participants discuss what NOS could be made visible in a common lab activity

- Short discussion of what kind of activities and NOS aspects the teachers would like to try in their own classrooms

Distributed material:

- Excerpts from descriptions of classroom activities:

- Excerpt from Black-box activity "the bucket" (Wickman and Persson 2009),

- Excerpt from SSI-approach "Can cell phones cause illness?” (Ekborg et al. 2012), +Newspaper articles about cell phones

- Translated excerpt of historical case study "the battle over the electron" (Kolstø 2008)

Planning of NOS teaching

- Participants make up joint plans for NOS teaching: choose key NOS aspects and issues, connect to curriculum; decide on possibilities for assessment

- The group is divided in two (year 1-6 and year 7-9 teachers) where detailed lesson plans are made. The groups present their thought to each other by the end of the meeting

- Practical plans for dates and classroom observations are made

Distributed material:

- List of formerly discussed aspects and issues

Reflection on implementation

- Each member shares their experiences from the implementation: details of the group, details from the activity, what NOS issues were targeted and how they were included, problems and achievements

- Teachers read two short descriptions of critical incidents ${ }^{\mathrm{b}}$ and discuss them from a NOS perspective

- Teachers get a task to prepare for the next meeting: to search for critical incidents in their own science lessons

Distributed material:

- Two written descriptions (translated) of critical incidents "Cells" and "Lamps" (Nott and Wellington 1998)

2:4 Critical incidents, teaching examples

- Participants describe and discuss their collected critical incidents ${ }^{b}$

- Discussion of five more critical incidents adjusted from Nott and Wellington (1998)

- Three new examples of NOS activities are distributed and demonstrated by the moderator (due to earlier request from the teachers). Followed by teachers' discussion about NOS and NOS teaching connected to the examples 
Table 5 (continued)

\begin{tabular}{l}
$\begin{array}{l}\text { Meeting } \\
\text { (year/group) }\end{array} \quad$ Summary description and distributed material \\
\hline
\end{tabular}

- Joint plans for next year: how do we proceed? Suggestions of trying a black-box activity at the beginning of the semester

Distributed material:

- Five written descriptions (translated) of critical incidents "The magnesium incident," "Rats," "Contraception," "Chemists," and "Predictions" (Nott and Wellington 1998)

- Excerpts from descriptions of classroom activities: "Mystery tube" (Lederman and Abd-El-Khalick 1998);"The scrambled sentence" (http://www.sciencelearn.org. nz/Nature-of-Science); Card game:"Which are scientific questions?" (created by the second author of this article and described in Hansson et al. 2014)

- Participants make detailed plans for teaching a black-box activity "the bucket" (Wickman and Persson 2009) that have been demonstrated to them earlier. Discussion of NOS aspects and connection to the curriculum

- Practical plans for dates and classroom observations are made

Distributed material: none

Reflection on implementation

- Short round of sharing of experiences from implementation of the black-box activity

- Reflections and comparisons between the black-box activity and the previously implemented NOS teaching session (year 2)

- (Contrary to the other meetings, in this focus group meeting the moderator was prepared with a battery of detailed questions about the activities Thus, the participants were not the owners of the discussion to the same extent as in former meetings)

Distributed material: none

3 NOS progression for compulsory school

- Participants get the task to, from the basis in their gained experiences, discuss what and how specific NOS issues are appropriate to teach at different educational stages (in a year 1-9 perspective). Notes are taken by one of the participants

Distributed material:

- Table with school years and themes for participants' documentation

Loose ends

- Discussions of teachers' ideas that have been recurrent in interviews, and informal discussions, but that have not been shared or thoroughly discussed in the focus group (e.g., washing powder lab, inquiry with many degrees of freedom)

- Revisiting progression: teachers discuss the researcher's preliminary analysis of their discussion from last time, make adjustments and put forward new suggestions

Distributed material:

- Excerpt from transcript of follow-up interview where John describes a teaching activity "the washing powder lab"

- Table over preliminary analysis

Summing up evaluations

- Written prompts and diagrams for teachers to answer/fill in providing their thoughts on their individual journeys through the project (example: how was your attitude and confidence in relation to your teaching affected by different parts of the project on a scale from zero to five?)

- Short discussion and sharing of evaluations

Distributed material:

- Written prompts and diagrams for evaluation

\footnotetext{
${ }^{\text {a }}$ An agreement was met that pre-distributed material never should exceed three pages

${ }^{\mathrm{b}} \mathrm{A}$ critical incident is defined as:

....an event which makes a teacher decide on a course of action which involves some kind of explanation of the scientific enterprise. It may be an event like some practical work going wrong or it may be an event which raises moral and ethical issues about scientific knowledge or the conduct of scientists. These events are often stimulated by pupils saying and doing things, but they may also arise through the action of the teacher, particularly when a demonstration goes wrong. (Nott and Wellington 1998, p.581)
} 
Open Access This article is distributed under the terms of the Creative Commons Attribution 4.0 International License (http://creativecommons.org/licenses/by/4.0/), which permits unrestricted use, distribution, and reproduction in any medium, provided you give appropriate credit to the original author(s) and the source, provide a link to the Creative Commons license, and indicate if changes were made.

\section{References}

Abd-El-Khalick, F. (2012). Nature of science in science education: toward a coherent framework for synergistic research and development. In B. J. Fraser, K. Tobin, \& C. McRobbie (Eds.), Second international handbook of science education (Vol. Vol. 2, pp. 1041-1060). Dordrecht: Springer.

Abd-El-Khalick, F., Bell, R. L., \& Lederman, N. G. (1998). The nature of science and instructional practice: making the unnatural natural. Science Education, 82(4), 417-436.

Aikenhead, G. S. (2006). Science education for everyday life : evidence-based practice. New York, NY: Teachers College Press.

Akerson, V. L., Buck, G. A., Donnelly, L. A., Nargund-Joshi, V., \& Weiland, I. S. (2011). The importance of teaching and learning nature of science in the early childhood years. Journal of Science Education and Technology, 20(5), 537-549.

Akerson, V. L., \& Hanuscin, D. L. (2007). Teaching nature of science through inquiry: results of a 3-year professional development program. Journal of Research in Science Teaching, 44(5), 653-680.

Allchin, D. (2003). Scientific myth-conceptions. Science Education, 87(3), 329-351.

Allchin, D. (2011). Evaluating knowledge of the nature of (whole) science. Science Education, 95(3), 518-542.

Allchin, D. (2012). The Minnesota case study collection: new historical inquiry case studies for nature of science education. Science \& Education, 21(9), 1263-1281.

Allchin, D. (2014). From science studies to scientific literacy: a view from the classroom. Science \& Education, 23(9), 1911-1932.

Bartholomew, H., Osborne, J., \& Ratcliffe, M. (2004). Teaching students “ideas-about-science": five dimensions of effective practice. Science Education, 88(5), 655-682.

Bell, R. L., Lederman, N. G., \& Abd-El-Khalick, F. (2000). Developing and acting upon one's conception of the nature of science: a follow-up study. Journal of Research in Science Teaching, 37(6), 563-581.

Brickhouse, N. W., \& Bodner, G. M. (1992). The beginning science teacher: classroom narratives of convictions and constraints. Journal of Research in Science Teaching, 29(5), 471-485.

Clough, M. P. (2011). The story behind the science: bringing science and scientists to life in post-secondary science education. Science \& Education, 20(7-8), 701-717.

Clough, M. P., \& Olson, J. K. (2012). Impact of nature of science and science education course on teachers' nature of science classroom practices. In M. S. Khine (Ed.), Advances in nature of science research: concepts and methodologies (pp. 247-266). Dordrecht: Springer.

Cobern, W. W., \& Loving, C. C. (1998). The card exchange: Introducing the philosophy of science. In W. F. McComas (Ed.), The nature of science in science education: rationales and strategies (pp. 73-82). Dordrecht: Kluwer Academic.

Dadachanji, D. K. (1998). The cultural challenge to scientific knowledge. World and I, 13, 172-178.

DeBoer, G. E. (2000). Scientific literacy: another look at its historical and contemporary meanings and its relationship to science education reform. Journal of Research in Science Teaching, 37(6), 582-601.

Duschl, R., Erduran, S., Grandy, R., \& Rudolph, J. (2006). Guest editorial: science studies and science education call for papers deadline: March 31, 2007. Science Education, 90(6), 961-964.

Erduran, S., \& Dagher, Z. R. (2014). Reconceptualizing the nature of science for science education: scientific knowledge, practices and other family categories. Dordrecht: Springer.

Ekborg, M., Ideland, M., Lindahl, B., Malmberg, C., Ottander, C., \& Rosberg, M. (2012). Samhällsfrågor i det naturvetenskapliga klassrummet. [Socieltal questions in the science calssroom]. Malmö: Gleerup.

Feinstein, N. (2011). Salvaging science literacy. Science Education, 95(1), 168-185.

Feinstein, N. W., Allen, S., \& Jenkins, E. (2013). Outside the pipeline: reimagining science education for nonscientists. Science, 340(6130), 314-317.

Freedman, K. L. (2009). Diversity and the fate of objectivity. Social Epistemology, 23(1), 45-56.

Gyllenpalm, J., Wickman, P.-O., \& Holmgren, S.-O. (2010). Teachers' language on scientific inquiry: methods of teaching or methods of inquiry? International Journal of Science Education, 32(9), 1151-1172.

Halkier, B. (2010). Fokusgrupper. [Fokus gropus] Malmö: Liber.

Hansson, L., \& Leden, L. (2016). Working with the nature of science in physics class: turning 'ordinary'classroom situations into nature of science learning situations. Physics Education, 51(5), 55001-55006. 
Hansson, L., Leden, L. \& Pendrill, A-M. (2014). Att arbeta med naturvetenskapernas karaktär i NOundervisningen. [To work with nature of science in science teaching]. LMNT-nytt, 2014:2.

Hanuscin, D. L., Lee, M. H., \& Akerson, V. L. (2011). Elementary teachers' pedagogical content knowledge for teaching the nature of science. Science Education, 95(1), 145-167.

Henke, A., \& Höttecke, D. (2015). Physics teachers' challenges in using history and philosophy of science in teaching. Science \& Education, 24(4), 349-385.

Herman, B. C., Clough, M. P., \& Olson, J. K. (2013). Teachers' nature of science implementation practices 2-5 years after having completed an intensive science education program. Science Education, 97(2), 271-309.

Herman, B. C., Clough, M. P., \& Olson, J. K. (2015). Pedagogical reflections by secondary science teachers at different NOS implementation levels. Research in Science Education, 47(1), 161-184.

Hodson, D. (1993). Philosophic stance of secondary school science teachers, curriculum experiences, and children's understanding of science: some preliminary findings. Interchange, 24(1-2), 41-52.

Hodson, D. (2008). Towards scientific literacy : a teacher's guide to the history, philosophy and sociology of science. Rotterdam: Sense Publishers.

Hodson, D., \& Wong, S. L. (2014). From the Horse's mouth: why scientists' views are crucial to nature of science understanding. International Journal of Science Education, 36(16), 2639-2665.

Hsieh, H.-F., \& Shannon, S. E. (2005). Three approaches to qualitative content analysis. Qualitative Health Research, 15(9), 1277-1288.

Högström, P., Ottander, C., \& Benckert, S. (2006). Lärares mål med laborativt arbete: Utveckla förståelse och intresse. Nordic Studies in Science Education, 2(3), 54-66.

Höttecke, D., \& Silva, C. C. (2011). Why implementing history and philosophy in school science education is a challenge: an analysis of obstacles. Science \& Education, 20(3-4), 293-316.

Irzik, G. (2010). Why should philosophers of science pay attention to the commercialization of academic science? EPSA Epistemology and Methodology of Science, 129-138.

Johansson, A.-M., \& Wickman, P.-O. (2012). What should students learn about scientific inquiry? A comparative study of 50 years of the Swedish national curricula. Nordic Studies in Science Education, 8(3), 197-212.

Knorr-Cetina, K. (1999). Epistemic cultures: how the sciences make knowledge. Cambridge: Harvard University Press.

Kolstø, S. D. (2008). Science education for democratic citizenship through the use of the history of science. Science \& Education, 17(8-9), 977-997.

Kvale, S. (1997). Den kvalitativa forskningsintervjun. Lund: Studentlitteratur.

Lakin, S., \& Wellington, J. (1994). Who will teach the 'nature of science'?: teachers' views of science and their implications for science education. International Journal of Science Education, 16(2), 175-190.

Latour, B. (1987). Science in action : how to follow scientists and engineers through society. Cambridge: Harvard Univ. Press.

Leden, L. (2017). Black \& white or shades of grey: teachers' perspectives on the role of nature of science in compulsory school science teaching. (Doctoral thesis, Malmö University, Malmö).

Leden, L., Hansson, L., Redfors, A., \& Ideland, M. (2015). Teachers' ways of talking about nature of science and its teaching. Science \& Education, 24(9-10), 1141-1172.

Leden, L., \& Hansson, L. (2017). Nature of science progression in school years 1-9: a case study of teachers' suggestions and rationales. Research in Science Education. https://doi.org/10.1007/s11165-017-9628-0.

Leden, L., \& Hansson, L. (forthcoming). Introducing the human elements of science in middle school through a context rich thematic project.

Lederman, N. G. (1995). Suchting on the nature of scientific thought: are we anchoring curricula in quicksand? Science \& Education, 4(4), 371-377.

Lederman, N. G. (2007). Nature of science: past, present, and future. In S. K. Abell \& N. G. Lederman (Eds.), Handbook of research on science education (pp. 831-879). Mahwah: Lawrence Erlbaum Associates, Publishers.

Lederman, N. G., Abd-El-Khalick, F., Bell, R. L., \& Schwartz, R. S. (2002). Views of nature of science questionnaire: toward valid and meaningful assessment of learners' conceptions of nature of science. Journal of Research in Science Teaching, 39(6), 497-521.

Lederman, N., \& Abd-El-Khalick, F. (1998). Avoiding de-natured science: activities that promote understandings of the nature of science. In The nature of science in science education: Rationales and strategies (pp. 83126). Dordrecht: Kluwer Academic.

Lederman, N. G., \& Lederman, J. S. (2012). Nature of scientific knowledge and scientific inquiry: building instructional capacity through professional development. In B. J. Fraser et al. (Eds.), Second international handbook of science education (Vol. Vol 1, pp. 335-359). Berlin: Springer.

Longino, H. E. (1990). Science as social knowledge: values and objectivity in scientific inquiry. Princeton: Princeton Univ. Press. 
McComas, W. F. (1998). The principal elements of the nature of science: dispelling the myths. In W. F. McComas (Ed.), The nature of science in science education: rationales and strategies (pp. 53-70). Dordrecht: Kluwer Academic.

Morgan, D. L. (1997). Focus groups as qualitative research. Thousand Oaks: Sage.

Mosco, V. (2012). Entanglements: between two cultures and beyond science wars. Science as Culture, 21(1), $101-115$.

Nott, M., \& Wellington, J. (1998). Eliciting, interpreting and developing teachers' understandings of the nature of science. Science \& Education, 7(6), 579-594.

Roberts, D. A. (2007). Scientific literacy/science literacy. In S. K. Abell \& N. G. Lederman (Eds.), Handbook of research on science education (pp. 729-780). Mahwah: Lawrence Erlbaum Associates, Publishers.

Roberts, D. A. (2011). Competing visions of scientific literacy. The influence of s science curriculum policy image. In C. Linder, L. Östman, D. A. Roberts, P.-O. Wickman, G. Erickson, \& A. MacKinnon (Eds.), Exploring the landscape of scientific literacy (pp. 11-27). London: Routledge.

Roberts, D. A., \& Bybee, R. W. (2014). Scientific literacy, science literacy, and science education. In N. G. Lederman \& S. K. Abell (Eds.), Handbook of research on science education (Vol. Vol 2, pp. 545-558). New York: Routledge.

Rudolph, J. L. (2005). Epistemology for the masses: The origins of "the scientific method" in American schools. History of Education Quarterly, 45(3), 341-376.

Ruhrig, J., \& Höttecke, D. (2015). Components of science teachers' professional competence and their orientational frameworks when dealing with uncertain evidence in science teaching. International Journal of Science and Mathematics Education, 13(2), 447-465.

Skolverket. (2011). Curriculum for the compulsory school system, the pre-school class and the leisure-time centre 2011. Stockholm: Swedish National Agency for Education.

Skolverket. (2016). Kommentarmaterial till kursplanen $i$ fysik [Commentary to the physics curriculum]. Stockholm: Swedish National Agency for Education.

Stenmark, M. (2004). How to relate science and religion: a multidimensional model. Grand Rapids, Mich.: Eerdmans.

Wong, S. L., \& Hodson, D. (2010). More from the horse's mouth: what scientists say about science as a social practice. International Journal of Science Education, 32(11), 1431-1463.

Wibeck, V. (2010). Fokusgrupper: om fokuserade gruppintervjuer som undersökningsmetod [Focus groups: on focused group interviews as a research method]. Lund: Studentlitteratur.

Wickman, P.-O., \& Persson, H. (2009). Naturvetenskap och naturorienterande ämnen i grundskolan : en ämnesdidaktisk vägledning. Stockholm: Liber.

Yacoubian, H. A. (2015). A framework for guiding future citizens to think critically about nature of science and Socioscientific issues. Canadian Journal of Science, Mathematics and Technology Education, 15(3), 248260.

Zacharia, Z., \& Barton, A. C. (2004). Urban middle-school students' attitudes toward a defined science. Science Education, 88(2), 197-222. 